\title{
The simulation coaching concept - A step towards expertise
}

\author{
Mari Salminen-Tuomaala,, Jaakko Hallila, Asta Niinimäki, Paula Paussu \\ School of Healthcare and Social Work, Seinäjoki University of Applied Sciences, Finland
}

Received: October 29, 2019

Accepted: December 30, 2019 Online Published: January 19, 2020

DOI: $10.5430 /$ jnep.v10n4p83

URL: https://doi.org/10.5430/jnep.v10n4p83

\begin{abstract}
Background and Objective: This paper presents a sub-study of an ongoing research and development project (August 1, 2017December 31, 2019), whose aim has been to use simulation-based coaching to meet social and healthcare staff's self-reported learning needs in 20 small and medium-sized enterprises in Finland. Two regional educational institutions are responsible for the management of the project. The study aim was to examine the development of self-rated professional competence and expertise of social and healthcare staff, following a simulation coaching project.

Methods: An electronic questionnaire was used to collect information about participants' self-rated expertise, first in November 2017 and again in May 2019 following the simulation-based coaching intervention. IBM SPSS for Windows 25 was used to analyse the data.

Results: The respondents appreciated simulation coaching as an effective way of developing expertise and the continuous learning skills of professionals. In this project, coaching was considered to be especially suitable for theoretical and practical management of acute situations; for keeping up with change in society; for anticipating development needs, and for promoting the attractiveness and competitiveness of the company where they worked.

Conclusions: The simulation coaching concept, which involves action-based and concrete ways of developing theoretical and practical competence, is well suited for social and healthcare professionals undertaking continuing education. Using the companies' own facilities facilitates participation and application of new knowledge and skills.
\end{abstract}

Key Words: Coaching, Competence, Expertise, Simulation, Skills, Quantitative research

\section{INTRODUCTION}

This article is based on an ongoing research and development project, whose purpose has been to develop the professional competence of social and healthcare personnel in small and medium-sized enterprises (SMEs) in one region in Finland. The underlying assumption of the project partners is that expertise can be reached by a combination of good initial education, work experience and continuing education based on self-reported learning needs. This continuing education program, targeted at SMEs, uses simulation-based learn- ing and coaching. Small and medium-sized enterprises, or SMEs, refers to companies with a maximum net turnover of 50 million euro and a maximum staff headcount of 250 (Directorate-General for Enterprise and Industry. ${ }^{[1]}$

\subsection{Development of expertise}

Expertise can be defined with help of other, partly overlapping concepts. Usually, expertise is seen to be based on a combination of qualifications (official degrees or diplomas) and competence, which can sometimes be achieved

\footnotetext{
* Correspondence: Mari Salminen-Tuomaala; Email: mari.salminen-tuomaala@ seamk.fi; Address: School of Healthcare and Social Work, Seinäjoki University of Applied Sciences, Finland.
} 
without official requirements. ${ }^{[2]}$ This study uses the concept professional competence to refer to an official qualification combined with the knowledge and skills required in the profession. The study starts with the following assumptions: Professional competence can mature into expertise with the accumulation of time and work experience, especially if a continuing education program based on learner needs is provided and deliberate reflection fostered. The impact of education, the development of the worker's personality and experiential knowledge, gained through repetition of typical tasks, are combined into evolving expertise. Secondly, although much of the literature on expertise seems to deal with clinical nurse consultants or specialists, or other advanced practice professionals, in this study expertise is not seen as a term that could be applied to advanced practice positions only. Instead, it is believed that different kinds of expertise can exist and that expertise also depends on contextual factors.

Definitions for expertise in social and healthcare industries typically integrate theoretical and practical competence complemented by a number of metacognitive skills. ${ }^{[3]}$ In expert health or social care professionals are, among other things, expected to be capable of critical thinking, clinical reasoning and decision-making, and to possess potential to change existing practices. ${ }^{[4,5]}$

Reflection-all those cognitive and affective functions, whose purpose is to process experiences and reach new levels of understanding - is seen as an essential constituent in metacognition, if not its synonym. Continuous reflection of one's action is necessary for expertise to develop. In practice, this mean analysing and looking at problems and challenges from multiple perspectives and attempting to seek creative solutions. In simulation-based education, deliberate reflection is encouraged during the debriefing sessions. ${ }^{[6]}$

Besides metacognitive skills, essential attributes to social and healthcare professionals involve interaction, teamwork and ethical competence. ${ }^{[7-9]}$ With growing expertise, these skills may find their expression in effective guidance, counselling and mentoring practices. ${ }^{[4,5]}$ This entails a development of certain skills properties, for example situational awareness, purposeful action ${ }^{[10]}$ and positive attitude to change. ${ }^{[9]}$ Situational awareness refers to the process of selecting and processing information, perceiving and comprehending what is occurring in the environment, and understanding how the situation might evolve. Situational awareness can be seen as a precursor to decision-making and an essential attribute contributing to safety. ${ }^{[11]}$

It has also been proposed that experts possess emotional intelligence, or are able to recognize and manage their emotions, recognize other people's emotions and use this information to guide their thinking and action. ${ }^{[5,8]}$ Experts are sensitive to change, and flexible in choosing their responses to various situations. ${ }^{[12-14]}$ An expert can bring an important contribution to networks and communities by engaging in multiprofessional collaboration. ${ }^{[15,16]}$ One more important expert role, that is acting as an advocate for clients and families, becomes possible when all these attributes and skills come together. ${ }^{[17-19]}$ The consequence is that patients, clients and their families are more commonly invited to become members of multiprofessional expert teams. ${ }^{[20]}$

Whatever the degree of creativity and insight brought to the practice in health and social services, expertise must evolve within the framework of evidence-based knowledge. ${ }^{[14,21,22]}$ This involves the application of reliable knowledge in decision-making, ${ }^{[23]}$ and deliberate knowledge transfer to practice ${ }^{[9,24]}$ to improve safety and care quality. ${ }^{[9,22]}$

Finally, it was been suggested that the evolving expertise and collaboration in and between social and health industries can also be approached from four perspectives, those of (a) established professions; (b) reflective expertise; (c) collective expertise, and (d) shared cognition and networked expertise. ${ }^{[20]}$ The structure of established professions, which today include nurses and social workers, has remained similar for a century, although the problems of clients and patients are increasingly complex. At the same time, the expertise represented by professions has become narrower and more specific, as in advanced practice positions. The second perspective, reflective expertise, refers to the professionals' awareness of their own role and framework and to their ability to base their decisions on analytical thinking, in dialogue with the problem, the client and the multiprofessional team. ${ }^{[20]}$ This dialogical, reflective expertise is seen as a prerequisite for the development of collective expertise. The term refers to the transition from working alone to flexible expertise created in multiprofessional teams and networks, as discussed by Engeström in 2002. The fourth perspective, shared cognition and networked expertise, means that the cognitive load is shared, so that each participating individual is responsible for some aspect of the overall task. This type of expertise is physically and socially decentralized. ${ }^{[20]}$

\subsection{Simulation}

The project described in this paper relies on simulation-based coaching in the continuous education of professionals on their journey towards expertise. In the past two decades, much of the research on learning has emphasised the social, contextual and experiential nature of learning. ${ }^{[25]}$ Simulationbased learning has been defined as a technique that can be used to replace or amplify real-life experiences to promote 
reflective learning. ${ }^{[26]}$ Simulations highlight values and attributes which are central to practice. ${ }^{[27]}$ They can involve role plays, task trainers, virtual reality simulations, table-top exercises and full immersion simulations with standardized clients or patients. Simulations can be used for a variety of purposes, for example to learn individual theoretical or practical competencies, or to improve and reform essential processes and systems within organizations. ${ }^{[28,29]}$

In nursing, simulation has been recommended as a method to support the ongoing acquisition of theoretical and practical competencies. The use of simulation has solved the problem of patient/client availability and the ethical question of practising with real patients. In the current outcomes-based education paradigm, simulations also represent a response to the need to assess and demonstrate competence; knowledge, skills and attitudes can be effectively assessed within various domains of clinical competence. ${ }^{[30]}$

Simulation has proved to be useful in bringing together multiple professions for team training and promotion of collaboration. Communication, coordination and collaboration are commonly targeted competencies, along with leadership, role clarity and situational awareness. ${ }^{[31-34]}$ The simulated scenarios allow professionals to reflect on their typical collaboration, which can lead to improved client and patient care and safety. ${ }^{[35-37]}$ It seems that the development of safety may often occur through the improvement of non-technical social, cognitive or personal resource skills. ${ }^{[38,39]}$ A combination of feedback and repetitive practice have been cited as the essential features that lead to effective learning at least in simulation-based medical education. Feedback and debriefing have traditionally been provided after the simulated scenarios, but they can also be provided within simulation, as in Rapid Cycle Deliberate Practice (RCDP). In RCDP, new information is introduced in small chunks and the learners receive feedback and coaching during the frequent pauses. ${ }^{[40]}$

The planning and implementation of simulated scenarios can easily be based on authentic experiences of patient or clients situations, and the scenarios can be very close to practice.$^{[41-43]}$ In situ simulations - scenarios conducted in actual patient care units- can be very effective for continuing education. ${ }^{[44]}$ In situ simulation means that the actual members of the care team use the resources and the equipment of their own unit. ${ }^{[45-47]}$ This blending of work and learning environments can help to detect hidden safety risks, develop safer practice and strengthen team work. ${ }^{[41,46-49]}$

\subsection{Aim}

The study aim was to examine the development of self-rated professional competence and expertise of social and health- care staff, following a simulation coaching project conducted in small and medium-sized enterprises in 2017-2019.

The research problem was: How did the self-rated expertise of social and healthcare staff develop following a simulation coaching intervention conducted in small and medium-sized enterprises?

\section{Methods}

\subsection{Setting and sample}

This paper presents a sub-study of a research and development project, started in August 2017 and completed at the end of this year (2019). The aim of the project was to use simulation-based learning and coaching to meet health and social care staff's self-reported learning needs in small and medium-sized enterprises. These companies are active in health and social services targeted at the elderly population, at clients with disabilities or mental health problems and at children in need of help and protection. Two regional educational institutions, a University of Applied Sciences and a Vocational Institution, are responsible for the management of the project.

The project involved (a) a mixed-method survey early in 2017 on participants' self-assessed competence and learning needs, followed by (b) simulation-based coaching sessions conducted in the enterprises' own facilities, and (c) another mixed-method survey on participants' self-assessed competence to evaluate the effectiveness of the interventions. Several articles dealing with the project results have been published recently, and some of the results are referred to in the results section of this paper. ${ }^{[50,51]}$ The focus of this article is on a statistical comparison between the two self-rated assessments.

The participants were recruited by telephone. Out of 60 enterprises contacted, 20 agreed to participate in the study. The project started with a survey on participants' self-assessed competence and learning needs $(n=125$, response rate $96 \%)$. The questionnaire, created for this project, was based on a systematic literature review and finalized in the project team. The questionnaire contained both quantitative $(n=44)$ and qualitative $n=4$ ) items. Respondents reported a variety of individual and collective learning needs, both theoretical and practical. Based on the assessment and consultation during company visits, it was decided that the simulationbased learning sessions should cover a wide range of topics, some of which could be labelled generic skills (teamwork, interaction and dialogue; emotional intelligence; information technology and digital skills including remote counselling), while others were associated with the type of clients in the enterprise (encountering children and their families or en- 
countering clients with mental health problems) or with the specific challenges in the participants' work (acute situations, clinical nursing skills, medication, or end-of-life care).

The 4-8-hour simulation-based coaching sessions were conducted in the enterprises' own facilities. A total of 120 sessions were delivered, always by two lecturers, selected based on their area of expertise. The sessions started with an overview of the simulation coaching method, followed by scenarios based on short descriptions and instructions. The participants worked in pairs selected by lot. After a preparation period (10-15 minutes) they acted out the scenario (10 minutes), while the other participants observed the situation from various perspectives, such as interaction, concrete interventions or the logic of the action. One lecturer assumed the role of a facilitator, and another acted the role of the patient/client or family member. The session ended with a constructive feedback and reflection session (45 minutes). For example, one simulation-based coaching session conducted in an elderly care facility involved a 78-client with diabetes, Parkinson's disease, and a recent diagnosis of Alzheimer's disease. The two participants first learnt about the client's medication and current symptoms on the morning of the imaginary shift. Their task was use of the ABCDE protocol to identify the reasons for the client's acute confusion and agitation, choose the appropriate care interventions and consult a physician. The behaviour of the lecturer playing the client's part suggested corticosteroid-induced psychosis. The observers were requested to pay attention to the use of the identification and response processes, to the nurse-client interaction and to the teamwork between the nurses.

The simulation coaching sessions were followed by the second survey in 2019. The same instrument was used, with a few additions. In this survey, the response rate was $86 \%$ $(n=107)$. Some participants had been compelled to withdraw from the project due to restructuring or closing of the enterprise. The survey revealed mostly good self-rated expertise, or theoretical, practical and interaction competence, and confidence in learning, problem-solving, and action-based learning. Learning to make better use of use digital tools, social media, electronic learning environments and remote counselling were found to be among the most salient learning needs.

\subsection{Data collection}

An electronic Webropol questionnaire was used to collect information about participants' self-rated expertise, first in November 2017, and the second time after the simulationbased coaching intervention in May 2019. Besides 8 demographic questions, both times the participants were asked to rate their skills and knowledge using by responding to 50 items on a 5-point Likert scale ( 1 = very good; 2 = fairly good, 3 = neutral (neither good nor poor); 4 = fairly poor and $5=$ very poor $)$.

\subsection{Data analysis}

The detailed results of the two surveys have been presented in earlier articles. [50,51] For this paper, the results from the two surveys conducted in 2017 and 2019 were compared using the Mann-Whitney u test and the Kruskal-Wallis test. ${ }^{[52]}$

IBM SPSS for Windows 25 was used to analyse the data. In both surveys, the results were examined by background variables divided into categories (age: $<40,40-49$ or $\geq 50$; and later: $\leq 45$ or $\geq 46$; education: vocational qualification, professional qualification or university; Degree title/diploma: practical nurse, nurse, Bachelor of Social Services, Youth and Leisure Instructor or other.) The results were presented using frequencies, percentages and central tendencies, and the associations to variables were studies by means of cross tabulation. Because of a skewed distribution, the Mann-Whitney $\mathrm{u}$ test and the Kruskal-Wallis test were employed to examine differences between various categories of respondents.

\subsection{Ethics and Study Strengths and Limitations}

The study observed national ethical principles and guidelines on good scientific practice. ${ }^{[53]}$ Participation was voluntary and the study was conducted anonymously. The staff in SMEs received the information about the study purpose and voluntary participation by e-mail. ${ }^{[52]}$ A decision to respond to the questionnaire was regarded as informed consent. ${ }^{[54]}$

To increase study reliability and validity, special emphasis was placed on careful preparation and testing of the questionnaire. An expert panel consisting of all members of the project team and steering group had an opportunity to make amendments before the first and second survey as a support to the operationalization process. ${ }^{[54]}$ The questionnaire was pretested for clarity and logic by ten persons from SMEs and the steering group in autumn 2017. The electronic survey system was also tested by two project team members before approaching the respondents. ${ }^{[55]}$

The response rates were high $(96 \%$ and $86 \%$ ) for both surveys. The fact that the respondents represented different educational backgrounds and workplaces can also be considered a strength. Despite all this, the generalizability of the results might be limited. The study setting was a culturally homogenous region, the participants had received their education in Finland and the majority of them were women. The high proportion of females can be explained by the skewed gender distribution in the health and social services. 


\section{Results}

\subsection{Participant demographics}

As shown in Table 1, the majority of the participants in both surveys were women $(84 \%(\mathrm{n}=104)$ in $2017 ; 88 \%(\mathrm{n}=93)$ in 2019). The age range of all participants varied between 19 and 62 years (mean age 42). Almost all respondents had a vocational qualification, diploma or a university degree but four few staff members only had a secondary level general education, and another four employees an upper secondary level general education. Practical nurses were the greatest group in both surveys; nearly half of the participants had a vocational qualification in practical nursing. Bachelors of Social Services and Nurses with Bachelor's degree or diplomas were the second most common groups, with almost equal shares. The majority of the nursing staff had specialized in the care of elderly clients and some in child care or mental health work. Approximately one fifth of the staff worked in administration. As is common in small enterprises, they had a double role as carers and leaders. Most of them were also entrepreneurs, or principal owners responsible for managing company finances.

Table 1. Participant demographics from 2017 and 2019

\begin{tabular}{|c|c|c|c|c|}
\hline \multirow{2}{*}{ Background variable } & \multicolumn{2}{|c|}{2017} & \multicolumn{2}{|c|}{2019} \\
\hline & $\mathbf{n}$ & $\%$ & $\mathbf{n}$ & $\%$ \\
\hline \multicolumn{5}{|l|}{ Age in years } \\
\hline$<40$ & 40 & 32 & 37 & 35 \\
\hline $40-49$ & 37 & 30 & 30 & 28 \\
\hline$\geq 50$ & 44 & 35 & 30 & 28 \\
\hline \multicolumn{5}{|l|}{ Gender } \\
\hline Female & 104 & 84 & 93 & 88 \\
\hline Male & 19 & 15 & 13 & 12 \\
\hline \multicolumn{5}{|l|}{ Education } \\
\hline Vocational qualification & 37 & 30 & 37 & 40 \\
\hline Professional qualification & 40 & 32 & 19 & 18 \\
\hline University of Applied Sciences degree & 35 & 28 & 33 & 31 \\
\hline \multicolumn{5}{|l|}{ Degree title or diploma } \\
\hline Nurse & 19 & 15 & 20 & 19 \\
\hline Bachelor of Social Services & 19 & 15 & 15 & 14 \\
\hline Practical Nurse & 59 & 47 & 52 & 49 \\
\hline Youth and Leisure Instructor & 3 & 3 & 5 & 5 \\
\hline Other title or diploma & 23 & 14 & 12 & 11 \\
\hline \multicolumn{5}{|l|}{ Scope of employment } \\
\hline Administration & 27 & 22 & 20 & 19 \\
\hline Guidance or counselling & 64 & 51 & 54 & 58 \\
\hline Promotion of clients' ability to function & 88 & 70 & 69 & 64 \\
\hline Basic client care & 77 & 62 & 72 & 67 \\
\hline Supporting growth and development & 45 & 36 & 36 & 34 \\
\hline
\end{tabular}

The group "other" (14\% in 2017 and 11\% in 2019) involved a physiotherapist, a teacher and a caretaker, to name a few.
The most common responses to the item about respondents' scope of employment were basic care of clients, guidance, counselling and promotion of clients' ability to function. A minority of the respondents mentioned subsidiary tasks or roles, for example as a team leader, driver or carer of animals.

\subsection{The development of expertise during the simulation coaching project}

A great deal of evidence was accumulated for the success of the simulation coaching intervention. Improvement was reported in several different areas of expertise.

To start with, comparing the results from the years 2017 and 2019, the Mann-Whitney u-test revealed a statistically very significant improvement in participants' knowledge of simulation-based learning $(p=.000)$. It was also found that the participants rated their continuous learning skills significantly higher in 2019 compared to the year 2017 ( $p=$ .008). The same result was obtained for the development of action-based learning $(p=.008)$.

Second, the participants reported improved management of acute situations. Their self-rated knowledge of how to guide and counsel clients facing illness was better in 2019 compared to 2017 ( $p=.015)$. The participants also felt better prepared to act in various acute situations $(p=.031)$ and to select optimal interventions to manage the acute situation $(p=.037)$. The improved skill to choose appropriate care or nursing interventions was not limited to acute situations alone; in the latter survey, the participants found that they were in general more competent in choosing interventions for their clients across a variety of situations. The difference between ratings from 2017 and 2019 was statistically very significant $(p=.006)$. In addition, a nearly significant improvement ( $p=.011)$ was detected in the participants' self-rated skills in supporting clients' family members.

Third, improvement was evident in another area important for the development of client work, that is keeping up with changes in society. The Mann-Whitney U test showed a statistically very significant change ( $\mathrm{p}=.008)$ from 2017 to 2019. The participants also reported improved skills in increasing the attractiveness of their company in the eyes of potential new recruits $(p=.010)$. They indicated some improvement in their ability to make the company more attractive to clients ( $p$ $=.045)$ and in their ability to enhance the competitiveness of their company in the market $(p=.030)$. The last two changes were statistically nearly significant.

Finally and importantly, significant improvement seems to have occurred in the participants' information and communication technology skills. This is the area, where most learning needs had been reported earlier. Statistically very 
significant improvements were reported from 2017 to 2019 in the following areas: Use of applications, for example Word or Excel ( $p=.003)$; use of social media $(p=.006)$; use of the Moodle learning environment $(p=.004)$, and use of digital tools for guidance and counselling $(p=.001)$. Additionally, statistically nearly significant improvements were observed in technological communication skills in general $(p=.012)$ and in remote counselling skills as part of client work ( $p=$ .016).

The participants did not report significant improvement in the identification of care or nursing needs or in counselling clients on physical or psychosocial function. No significant differences were discerned between the various groups of participants (by age, education or degree title/diploma).

\subsection{Discussion}

The simulation coaching described in this paper can be considered a success. The participants reported improvement in areas earlier assessed by them as the most significant learning targets. The ratings presented are further evidence for the participants' satisfaction, reported earlier for the same group of respondents. An earlier study revealed that nearly half of them found that the simulation coaching had very well met their learning needs, and further $41 \%$ found that their learning needs had been met fairly well. The same report showed that the majority of the participants agreed that their professional competence had improved very well $(43 \%)$ or fairly well $(39 \%) .^{[51]}$

The modest or non-existent improvement in some areas, for example in the identification of care or nursing needs or in counselling clients on physical or psychosocial function, can most probably be explained by the fact that the participant ratings for these skills were already high before the coaching intervention. These are tasks carried out on a daily basis and seem to fall into the participants' area of expertise.

The participants' improved management of acute situations and better preparedness to choose appropriate care or nursing interventions were among the most notable developments during this project. The simulated scenarios allowed participants to practise fast decision-making required in acute situations, without risk of jeopardising patient safety. Simulation, combined with feedback and discussion, can be very helpful in improving learners' self-confidence.

Much of the change reported by the participants can be seen as essential for the continuous future development of their professional competence and expertise. Improved information and communication technology skills, as well as better continuous learning skills and keeping up with changes in society, can all be considered valuable in this sense, also from the perspective of the organization. The participants also reported being now better prepared to improve the attractiveness of their company in the market. The earlier study conducted with the same participants produced similar results: The great majority of the respondents found that they had been able to use and apply to their work the knowledge and skills learnt during the simulation coaching, either very well $(33 \%)$ or fairly well $(50 \%) .{ }^{[51]}$ The ability to select and apply what one has learnt, or to transfer skills and knowledge to practice, is crucial in complex decision-making situations, especially with the increasing flow of information in a digital working environment.

Finally, it can be hypothesized that the discussions, feedback and reflection, which were an important part of the simulation coaching process, might per se promote the participants' growth into expertise. The learning experience may provide an incentive for further reflection as part of everyday work life. We can also hope that the changes reported will promote use of evidence-based knowledge. It might also be claimed that the expertise required from professionals working in small and medium-sized enterprises is different compared to the expertise of advanced practice professionals. It may not be as specific or in-depth, but it covers a wide range of competencies and is possible more focused on the practical, contextual and experiential aspects of work.

Great numbers of new staff will be required in a few years, as both the population and the workforce are rapidly ageing in western societies. Simulation-based coaching, tailored to individual learner needs, might provide one tool to be used in making the social and healthcare industries more attractive to new recruits. Simulation can also be used to improve information and communication technology skills in a field currently not known for being very technology-oriented.

\section{Conclusion}

The simulation coaching concept introduced in this paper is well suited for social and healthcare professionals undertaking continuing education. Thoroughly conducted learning needs assessments, careful planning and the use of the companies' own facilities helps to meet specific needs of staff in small and medium-sized enterprises. The simulation coaching concept can easily be tailored to the needs of social and healthcare professionals. In situ-simulation, or using the companies' own facilities and resources, facilitates participation and application of new knowledge and skills.

\section{CONFLicts OF InTEREST Disclosure}

The authors declare that they have no competing interests. 


\section{REFERENCES}

[1] European Commission. Evaluation of the SME definition. 2014. Available from: https://publications.europa.eu/en/publ ication-detail/-/publication/5849c2fe-dcd9-410e-a f $37-1 \mathrm{~d} 375088 \mathrm{e} 886$

[2] Sipilä A. Sosiaalityön asiantuntijuuden ulottuvuudet. Tiedot, taidot ja etiikka työntekijöiden näkökulmasta kunnallisessa sosiaalityössä (Dimensions of social work expertise. Knowledge, skills and ethics from an employee's standpoint in municipal social work). Academic dissertation. University of Eastern Finland, Faculty of Social Sciences and Business Studies. Publications of the University of Eastern Finland, Dissertations in Social Sciences and Business Studies No $28 ; 2011$.

[3] Korhonen A, Korhonen T, Holopainen A. Asiantuntijuus ja näyttöön perustuva toiminta. [Experts facilitate evidence-based practice.] Tutkiva hoitotyö. 2010; 8(3): 38-42.

[4] Mantzoukas S, Watkinson S. Review of advanced nursing practice: the international literature and developing generic features. J Clin Nurs. 2006; 16: 28-37. PMid:17181664 https://doi.org/10.1 $111 / j .1365-2702.2006 .01669 . x$

[5] Stevenson K, Ryan S, Masterson A. Nurse and allied health professional consultants: perceptions and experiences of the role. J Clin Nurs. 2011; 20: 537-44. PMid:21219527 https://doi.org/10.1 $111 / j \cdot 1365-2702.2010 .03506 . x$

[6] Eikeland Husebø S, O'Regan S, Nestel D. Reflective Practice and Its Role in Simulation. Clinical Simulation in Nursing. 2015; 11(8): 368-375. https://doi .org/10.1016/j.ecns. 2015.04.005

[7] Manley K, Webster J, Hale N, et al. Leadership role of consultant nurses working with older people: a co-operative inquiry. J Nurs Manag. 2008; 16: 147-58. PMid:18269545 https ://doi.org/10 $.1111 / j .1365-2834.2007 .00843 . x$

[8] Redwood S, Lloyd H, Carr E, et al. Evaluating nurse consultants' work though key informant perceptions. Nurs Stand. 2007; 21: 35-40. https://doi.org/10.7748/ns.21.17.35.s51

[9] Woodward VA, Webb C, Prowse M. Nurse consultants: their characteristics and achievements. J Clin Nurs. 2005; 14: 845-54. PMid: 1600009 https://doi.org/10.1111/j.1365-2702.20 05.01165. $\mathrm{x}$

[10] Benner P, Tanner C, Chesla C. Expertise in nursing practice. Caring, clinical judgment, and ethics. 2nd ed. Springer Publishing Company; 2009.

[11] Fore S. A concept analysis of situational awareness in nursing. J Adv Nurs. 2013; 69(12): 2613-21. PMid:23528125 https://doi.org/ $10.1111 / j$ an. 12130

[12] O'Connor M, Chapman Y. The palliative care clinical nurse consultant: An essential link. Collegian 2008; 15: 151-7. PMid:19112925 https://doi.org/10.1016/j.colegn.2008.06.002

[13] Bloomer MJ, Cross WM. An exploration of the role and scope of the Clinical nurse consultant (CNC) in a metropolitan health service. Collegian 2010; 18: 61-9. PMid:21706993 https ://doi .org/10 $.1016 / j$. colegn. 2010.09.002

[14] Mullen C, Gavin-Daley A, Kilgannon H, et al. Nurse Consultants 10 years on: insight to the role for Nurse Managers. J Nurs Manag. 2011; 19: 820-31. PMid:21899635 https://doi .org/10.1111/ j.1365-2834.2011.01284.x

[15] Hakkarainen K, Lallimo J, Toikka S. Asiantuntijuus, kollektiivinen luovuus, jaetut tietokäytännöt (Expertise, collective creativity, shared knowledge practices). 2012. Available from:https://s3. amazonaws. com/academia. edu.document s/3122177/Hakkarainen_K_Lallimo_J_-_Toikka_S__arvi oitavana__Asiantuntijuus__kollektiivinen_luovuus_-_ ja_jaetut_tietokaytannot.pdf?response-contentdisp osition=inline $\% 3 \mathrm{~B} \% 20 \mathrm{filename} \% 3 \mathrm{DHakkarainen} \mathrm{K} \_$Lalli mo_J_and_Toikka_S_201.pdf\&X-Amz-Algorithm=AWS4-HMA C-SHA256\&X-Amz-Credential=AKIAIWOWYYGZ2Y53UL3A\%2F2 0190814\%2Fus-east-1\%2Fs3\%2Faws4_request\&X-Amz-Dat $e=20190814 \mathrm{~T} 082524 \mathrm{Z} \& \mathrm{X}-$ Amz-Expires $=3600 \& \mathrm{X}-$ Amz-Signe dHeaders $=$ host \&X-Amz-Signature $=79 \mathrm{c} 81 \mathrm{e} 2 \mathrm{ecc} 3 \mathrm{f} 27 \mathrm{ef} 946$ dc8091e86c589ac62382d10ede2b85db4a2f 8f6e58d46

[16] Sosiaali - ja terveysministeriö (Ministry of Social Affairs and Health in Finland) Koulutuksella osaamista asiakaskeskeisiin ja moniammatillisiin palveluihin. Ehdotukset hoitotyön toimintaohjelman pohjalta (Education as a means to promote client-centred and multiprofessional services). Reports and memorandums of the Ministry of Social Affairs and Health in Finland 7. 2012.

[17] Glover DE, Newkirsk LE, Cole LM, et al. Perioperative Clinical Nurse Specialist role delineation: a systematic review. AORN J. 2006; 84(6): 1017-30. https://doi.org/10.1016/S0001-209 2 (06) 63999-9

[18] Lewandowski W, Adamle K. Substantive areas of Clinical Nurse Specialist practice: a comprehensive review of the literature. Clin Nurse Spec. 2009; 23(2): 73-90. PMid:19225287 https ://doi.or g/10.1097/NUR . 0b013e31819971d0

[19] Moore J, McQuestion M. The Clinical Nurse Specialist in chronic diseases. Clin Nurse Spec. 2012; 26(3): 149-63. PMid:22504473 https://doi.org/10.1097/NUR.0b013e3182503fa7

[20] Isoherranen K. Uhka vai mahdollisuus - moniammatillista yhteistyötä kehittämässä (Threat or possibility- developing interprofessional collaboration). Academic dissertation. University of Helsinki. Faculty of Social Sciences. 2012.

[21] Humphreys A, Johnson S, Richadson J, et al. A systematic review and meta-synthesis: evaluating the effectiveness of nurse, midwife/allied health professional consultants. J Clin Nurs. 2007; 16: 1792-808. PMid:17880468 https://doi .org/10.1111/j.1365-2702.20 $07.01757 . x$

[22] Walker JA, Urden LD, Moody R. The Role of the CNS in achieving and maintaining magnet status. J Nurs Adm. 2009; 39 (12): 515-23. PMid:19955965 https://doi.org/10.1097/NNA.0b013e3181 c1803a

[23] ICN. 2012. The ICN code of ethics for nurses. Available from: http://www.icn.ch/images/stories/documents/ab out/icncode_english.pdf

[24] Profetto-McGrath J, Smith KB, Hugo K, et al. Clinical Nurse Specialists' use of evidence in practice: a pilot study. Worldviews Evid Based Nurs. 2007; 4(2): 86-96. PMid:17553109 https://doi.or $\mathrm{g} / 10.1111 / \mathrm{j} .1741-6787.2007 .00086 . \mathrm{x}$

[25] Reedy GB. Using cognitive load theory to inform simulation design and practice. Clin Simul Nurs. 2015; 11(8): 355-60. https: //doi.org/10.1016/j.ecns. 2015.05.004

[26] Gaba DM. The future vision of simulation in healthcare. Simul Healthc. 2007; 2(2): 126-35. PMid:19088617 https://doi.or g/10.1097/01.SIH.0000258411.38212.32

[27] Kelly MA, Hager P. Informal learning: relevance and application to health care simulation. Clin Simul Nurs. 2015; 11(8): 376-82. https://doi.org/10.1016/j.ecns.2015.05.006

[28] Driver JE, Gaba DM, Lighthall GK. The benefits of using simulation in risk management and patient safety. In: B Youngberg, ed. Principles of risk management and patient safety. London: Jones and Bartlett. 2011.

[29] Drupsteen L, Guldenmund FW. What is learning? A review of the safety literature to define learning from incidents, accidents and disasters. JCCM. 2014; 22(2): 81-96. https ://doi .org/10.1111/ 1468-5973.12039 
[30] Scalese RJ, Obeso VT, Issenberg SB. Simulation technology for skills training and competency assessment in medical education. J Gen Intern Med. 2008; 23(Suppl 1): 46-9. PMid:18095044 https : //doi.org/10.1007/s11606-007-0283-4

[31] Buljac-Samardzic M, Dekker-van Doorn CM, van Wijngaarden JDH, et al. Interventions to improve team effectiveness: a systematic review. Health Policy. 2010; 94(3): 183-95. PMid:19857910 https://doi.org/10.1016/j.healthpol.2009.09.015

[32] Eppich W, Howard V, Vozenilek J, et al. Simulation-based team training in healthcare. Simul Healthc. 2011; 6(7) (Suppl): S14-19. PMid:21817858 https://doi.org/10.1097/SIH.0b013e3182 $29 f 550$

[33] Manser T. Teamwork and patient safety in dynamic domains of healthcare: a review of the literature. Acta Anaesthesiol Scand. 2009; 53: 143-51. PMid:19032571 https://doi.org/10.1111/j.1399-6 $576.2008 .01717 . \mathrm{x}$

[34] Weaver SJ, Lyons R, DiazGranados D, et al. The anatomy of health care team training and the state of practice: a critical review. Acad Med. 2010; 85: 1746-60. PMid:20841989 https ://doi .org/10 .1097/ACM. Ob013e3181f2e907

[35] Schmidt E, Goldhaber-Fiebert SN, Ho LA, et al. Simulation exercises as a patient safety strategy: a systematic review. Ann Intern Med. 2013; 158(5): 426-32. PMid:23460100 https://doi.org/10.7 326/0003-4819-158-5-201303051-00010

[36] van Soeren M, Devlin-Cop S, MacMillan K, et al. Simulated interprofessional education: an analysis of teaching and learning processes. J Interprof Care. 2011; 25(6): 434-40. PMid:21899398 https://doi.org/10.3109/13561820.2011.592229

[37] von Wendt CE, Niemi-Murola L. Simulation in interprofessional clinical education:exploring validated nontechnical skills measurement tools. Simul Healthc. 2018; 13(2): 131-8. PMid:29117089 https://doi.org/10.1097/SIH.0000000000000261

[38] Komasawa N, Berg BW. 2016. A proposal for modification of nontechnical skill assessment for perioperative crisis management simulation training. J Clin Anesth. 2016; 32: 25-6. PMid:27290938 https://doi.org/10.1016/j.jclinane.2015.12.031

[39] Langdalen H, Abrahamsen EB, Sollid SJM, et al. A comparative study on the frequency of simulation-based training and assessment of non-technical skills in the Norwegian ground ambulance services and helicopter emergency medical services. BMC Health Serv Res. 2018. PMid:29970079 https ://doi .org/10.1186/s12913-018-332 5-1

[40] Chancey RJ, Sampayo EM, Lemke DS, et al. Learners' experiences during rapid cycle deliberate practice simulations: a qualitative analysis. Simul Healthc. 2019; 14(1): 18-28. PMid:30216277 https://doi.org/10.1097/SIH.0000000000000324

[41] Barton G, Bruce A, Schreiber R. Teaching nurses teamwork: integrative review of competency-based team training in nursing education. Nurse Educ Pract. 2018; 32: 129-37. PMid:29287747 https://doi.org/10.1016/j.nepr.2017.11.019

[42] Macrae C. Imitating incidents. How simulation can improve safety investigation and learning from adverse events. Simul Healthc. 2018;
13(4): 227-32. PMid:29771816 https : //doi .org/10.1097/SIH . 0000000000000315

[43] Stirling K, Smith G, Hogg G. The benefits of a ward simulation exercise as a learning experience. Br J Nurs. 2012; 21(2): 116-22. PMid:22306641 https://doi.org/10.12968/bjon. 20 12.21 .2 .116

[44] Rosen MA, Hunt EA, Pronovost PJ, et al. In situ simulation in continuing education for the health care professions: a systematic review. J Contin Educ Health Prof. 2012; 32(4): 234-54. PMid:23280527 https://doi.org/10.1002/chp. 21152

[45] Kobayashi L, Patterson MD, Overly FL, et al. Educational and research implications of portable human patient simulation in acute care medicine. Acad Emerg Med. 2008; 15: 1166-74. PMid:18638036 https://doi.org/10.1111/j.1553-2712.2008.00179.x

[46] Miller K, RileyW, Davis S. Identifying key nursing and team behaviours to achieve high reliability. J Nurs Manag. 2009; 17: 247-55. PMid:19416429 https://doi.org/10.1111/j.1365-2834.20 09.00978.x

[47] Nunnink L, Welsh AM, Abbey M, et al. In situ simulation-based team training for postcardiac surgical emergency chest reopen in the intensive care unit. Anaesth Intensive Care. 2009; 37: 74-8. PMid:19157350 https://doi.org/10.1177/0310057X090370 0109

[48] Ballangrud R, Hall-Lord ML, Hedelin B, et al. Intensive care unit nurses' evaluation of simulation used for team training. Nurs Crit Care. 2013; 19(4): 175-84. PMid:24750224 https://doi.org/10 .1111/nicc. 12031

[49] Patterson MD, Geis GL, Falcone RA, LeMaster T, Wears R. In situ simulation: detection of safety threats and teamwork training in a high risk emergency department. BMJ Qual Saf. 2013; 22(6): 468-77. PMid:23258390 https://doi .org/10.1136/bmjqs-2012-000 942

[50] Salminen-Tuomaala M, Kangasluoma E, Paavola K, et al. Health and social welfare professionals' self-rated competence and feedback following a simulation-based coaching intervention in small and medium-sized enterprises. Clin Nurs Stud. 2019; 7(4): 1-11. https://doi.org/10.5430/cns.v7n4p30

[51] Salminen-Tuomaala M, Paavola K, Paussu P. Health and social care leaders' self-rated competence and learning needs in small and medium-sized enterprises. Clin Nurs Stud. 2019; 7(2): 62-70. https://doi.org/10.5430/cns.v7n2p62

[52] Burns N, Grove S. The practice of nursing research: appraisal, synthesis, and generation of evidence. St Louis: Saunders. 2016.

[53] TENK (Finnish Advisory Board on Research Integrity). Responsible conduct of research and procedures for handling allegations of misconduct in Finland 2012. (In Finnish, Swedish and English). Available from: http://www.tenk.fi/files/HTK_ohje_2013.pdf

[54] Kankkunen P, Vehviläinen-Julkunen K. Tutkimus hoitotieteessä (Research in nursing science). Sanoma Pro Oy. 2018.

[55] Heikkilä T. Tilastollinen tutkimus (Statistical research). 9th ed. Helsinki: Edita Publishing Oy. 2014. 